\title{
Kinetic Analysis on Cell Growth and Biosynthesis of Poly (3-Hydroxybutyrate) (PHB) in Cupriavidus Necator H16
}

\author{
Maksudur Rahman Khan, D. M. Reddy Prasad, Hamidah Abdullah, \\ and Abeed Fatima Mohidin Batcha
}

\begin{abstract}
Poly (3-hydroxybutyrate) (PHB) is a biodegradable polymer that can be synthesized through bacterial fermentation. In this study, Cupriavidus necator $\mathrm{H16}$ was used to synthesize PHB by using jatropha oil as its sole carbon source. Experiments using $12.5 \mathrm{~g} / \mathrm{L}$ of jatropha oil with the highest PHB accumulation of $8.6 \mathrm{~g} / \mathrm{L}$ at $61.5 \mathrm{hr}$ was used to assess its kinetic pattern. Logistic and Leudeking-Piret model was used to evaluate the cell growth and PHB accumulation respectively and the theoretical values obtained corresponded well with the experimental data with slight deviation in cell growth and PHB accumulation at the end of stationary phase.
\end{abstract}

Index Terms-Cupriavidus necator, jatropha oil, kinetic model, poly (3-hydroxybutyrate).

\section{INTRODUCTION}

The current concerns over the increasing usage of nonbiodegradable plastics and its impact to the nature have pushed researchers to develop bioplastics that are biodegradable and environmental-friendly. These bioplastics are mainly polyesters of polyhydroxyalkanoate (PHA) polymers which are produced by various microbes under nutrient-limiting conditions (e.g.: limitation of sodium and phosphorus) but with an excess of carbon source [1].

PHAs are $100 \%$ biodegradable and biocompatible polymers with properties such as thermoplastic, elastomer, insoluble in water and also non-toxic in nature [2]. These polyesters have characteristics similar to those of polyethene and polypropylene, and can therefore be used instead of conventional plastics. One particular example of PHA is Poly (3-hydroxybutyrate) (PHB) which is a homopolymer that contains monomers of 3-hydroxybutyrate It has crystalline properties with a melting point of around $170^{\circ} \mathrm{C}$ [3]. PHA has garnered great interest due to its biodegradability and biocompatibility with properties such as non-toxic, optically-active, and insoluble in water [2]. PHAs non-toxic property also makes it suitable for use in medical, pharmaceutical and also food industries [4].

Nevertheless, usages of bioplastics from PHA are still limited mainly because its production cost is still very high when compared to petroleum-based polyesters. Previous researches have proven that using substrate from pure

Manuscript received March 29, 2013; revised May 30, 2013. This work was funded by Malaysian Ministry of Higher Education under Grant GRS110320.

Maksudur Rahman Khan, D. M. Reddy Prasad, Hamidah Abdullah, and Abeed Fatima Mohidin Batcha are with Faculty of Chemical Engineering and Natural Resources, Universiti Malaysia Pahang, Lebuhraya Tun Razak, 26300 Gambang, Kuantan, Pahang, Malaysia (e-mail: mrkhancep@yahoo.com). glucose or sucrose can be rather expensive for large scale production. At USD 16/kg, the production cost of bioplastics from glucose would be 18 times higher than the conventional polypropylene plastics [6]. Since approximately $50 \%$ of PHA net production cost comes from the cost of its raw material [7], utilizing plant oil as the carbon source for PHA synthesis might reduce the PHA production cost and thus making large-scale PHA production a more feasible approach.

Meanwhile, researchers have also focussed on the idea of using industrial and municipal wastes for the synthesis of PHA. Previous researches have reported the use of various industrial wastes such as activated sludge, dairy waste, cheese whey, molasses and so on. In a research done by Chua et al. [8], it was shown that PHA accumulation was higher with slight alteration of the sludge by adding acetate into the municipal wastewater to give a PHA yield of up to $30 \%$ of the sludge's dry weight. Studies done by Rogers and $\mathrm{Wu}$ [9] suggested the use of enhanced biological phosphorus removal (EBPR) in activated sludge to give a yield of 50\% PHA content under aerobic and anaerobic condition Cheese whey is another type of solid waste that can be used for PHA synthesis. As a by-product of dairy industry, it is considered as a pollutant due to its high content of [10]. In a study done by Pandian et al. [11] a yield of up to $11.32 \mathrm{~g} / \mathrm{L}$ of PHB dry weight was obtained by using this dairy waste as their main substrate.

Utilizing industrial wastes as carbon source for PHA production might prove to be valuable since this approach has an added advantage of reducing sludge handling cost. However, the low yield of PHA obtained from this approach may not be feasible for large-scale PHA production. Previous researches such as the ones done by Park DH [12] gave promising results with up to $83 \%$ of PHB content with soybean oil as their carbon source. Meanwhile, LópezCuellar et al. [13] achieved 92\% PHA content from fedbatch fermentation of Cupriavidus necator sp. by using canola oil as their carbon source. Similarly, Ng et al. [14] reported a total of $87 \%$ of $\mathrm{PHB}$ accumulation from the fermentation of Cupriavidus necator $s p$. by using jatropha oil as their main feedstock. Jatropha oil is known to have a high saturated fatty acid content [14] which will facilitate the synthesis of PHB. Apart from that, $C$. necator has been proven to accumulate PHB up to $80 \%$ of its cell dry weight [15].

Nonetheless, to ensure the efficiency of PHB production, it is essential to have a clear-cut mathematical model that could express the kinetic parameters such as cell dry weight and PHB concentration. A well-defined kinetic model could facilitate in problem-solving during large-scale fermentation 
process. In addition, it could also increase the production efficiency resulting in a better PHB yield. In the present study, poly-3-hydroxybutyrate (PHB) will be produced from the fermentation of $C$. necator using jatropha oil as its main carbon source. Although there were few reports on PHB production from jatropha oil, the kinetics involved during the bacterial fermentation still remain unclear. Therefore, this research focusses on establishing the kinetic study in predicting the metabolism of PHB production. We evaluated the effect of different variables (urea and oil concentration, agitation rate, etc.) on PHB production in our previous study (data not presented). From the results obtained, the kinetic model for cell growth and PHB production were fitted with our experimental data.

\section{MAterials AND Methods}

\section{A. Microorganism and Culture Media}

C. necator H16 (ATCC 17699) was used throughout this study. The mineral medium for the flask culture contained

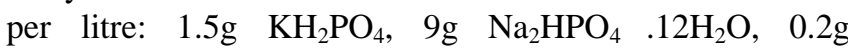
$\mathrm{MgSO} .7 \mathrm{H}_{2} \mathrm{O}, 1 \mathrm{~g}$ urea and $1 \mathrm{~mL}$ of trace element solution. Trace element solution contained per litre of $\mathrm{HCl} 0.1 \mathrm{~N}$ solution: $0.3 \quad \mathrm{~g}_{3} \mathrm{H}_{3} \mathrm{BO}_{3}, \quad 0.2 \quad \mathrm{~g} \quad \mathrm{CoCl}_{2} \cdot 6 \mathrm{H}_{2} \mathrm{O}, \quad 0.1 \mathrm{~g}$ $\mathrm{ZnSO}_{4} \cdot 7 \mathrm{H}_{2} \mathrm{O}, 30 \mathrm{mg} \mathrm{MnCl}_{2} \cdot 4 \mathrm{H}_{2} \mathrm{O}, 30 \mathrm{mg} \mathrm{Na} \mathrm{NoO}_{4} \cdot 2 \mathrm{H}_{2} \mathrm{O}$, $20 \mathrm{mg} \mathrm{NiCl} \cdot 6 \mathrm{H}_{2} \mathrm{O}$ and $10 \mathrm{mg} \mathrm{CuSO} \cdot 5 \mathrm{H}_{2} \mathrm{O}$. Jatropha oil was autoclaved separately before it was added to the culture medium.

\section{B. Growth Conditions}

$C$. necator was pre-cultivated in nutrient-rich medium consisting of $2 \mathrm{~g} / \mathrm{L}$ yeast extract, $10 \mathrm{~g} / \mathrm{L}$ meat extract and 10 $\mathrm{g} / \mathrm{L}$ peptone. $12100 \mathrm{~mL}$ shake flask containing $12.5 \mathrm{~g} / \mathrm{L}$ jatropha oil and $10 \mathrm{~mL}$ mineral medium was inoculated with $400 \mu \mathrm{L}$ of the pre-culture and incubated at $30^{\circ} \mathrm{C}$ and $200 \mathrm{rpm}$ for 100 hours unless stated otherwise. The jatropha oil concentration used was based on previous study done by $\mathrm{Ng}$ et al. [14] on production of PHB from jatropha oil. To study the kinetics of PHB synthesis, one shake flask was taken at a certain time interval and the culture was centrifuged $(8000$ $\mathrm{rpm}, 10 \mathrm{~min}, 4^{\circ} \mathrm{C}$ ) in a pre-weighed centrifuge tube. Cell pellets were centrifuged twice after washing with hexane and distilled water respectively. The washed cell pellets were frozen at $-20^{\circ} \mathrm{C}$ for $24 \mathrm{~h}$. These procedures were repeated for all the shake flasks and the frozen cell pellets were freeze dried and the cell dry weight (CDW) were obtained.

\section{Analytical Procedure}

The PHB concentration was determined with slight modifications from the method suggested by G. Braunegg et al. [16]. Approximately 10 to $20 \mathrm{mg}$ of lyophilized cells were subjected to methanolysis with $4 \mathrm{~mL}$ of acidified methanol (10\% (v/v) sulphuric acid) and $2 \mathrm{~mL}$ of chloroform for 4 hours. 20mg of benzoic acid was also used as internal standard. The resulting 3-hydroxybutyric methyl esters (HBME) were analyzed by Gas Chromatography (GC) (6890N Series, Agilent Inc.) using HP-Innowax $(30 \mathrm{~m} \times$ $0.25 \mathrm{~mm} \times 0.15 \mu \mathrm{m})$. Initial column temperature was set to $80^{\circ} \mathrm{C}$ with a temperature ramp of $5^{\circ} \mathrm{C} / \mathrm{min}$ until a final temperature of $240^{\circ} \mathrm{C}$ was reached. Helium was used as carrier gas at a flow rate of $20 \mathrm{~mL} / \mathrm{min}$. Known amounts of pure PHB was treated similarly to obtain a calibration curve and the resulting PHB concentration was calculated based on the HBME peak areas obtained from the chromatograms.

\section{Kinetic Modelling of Cell Growth and PHB Production}

1) Cell growth rate

Logistic equation, a substrate-independent model was used to represent the rate of cell growth by determining the inhibition effect on cell growth. The logistic equation, originally proposed by Verhulst [17], can be described as follows:

$$
\frac{d x}{d t}=\mu_{m} x\left(1-\frac{x}{x_{m}}\right)
$$

where $\mu_{m}$ is the maximum specific growth rate $\left(\mathrm{h}^{-}\right)$and $x_{m}$ is the maximum cell concentration $(\mathrm{g} / \mathrm{L})$. The integrated form of eqn (1) gives the value of $x$ as a function $t$.

$$
\begin{gathered}
x=x_{0}, t=t_{0}, \\
\text { Integrate to give } x=\frac{x_{0} e^{\mu_{m} t}}{\left(1-\frac{x_{0}}{x_{m}}\right)\left(1-e^{\mu_{m} t}\right)} t \leq t_{m}
\end{gathered}
$$

Rearrangement of equation (2) gives

$$
\ln \left(\frac{x}{\left.x_{m}-x\right)}=\mu_{m} t-\ln \left(\frac{x_{m}}{x_{0}}-1\right)\right.
$$

\section{2) PHB production rate}

Since PHB synthesis in C. necator occurs during both exponential and stationary phase, Mulchandani et. al, [18] had suggested the use of Leudeking-Piret model to represent the PHB production rate associated with both the growth and non-growth stage. The model, originally proposed by Luedeking and Piret [19] can be described as follows:

$$
\frac{d p}{d t}=\alpha \frac{d x}{d t}+\beta x
$$

whereby $\alpha$ and $\beta$ are the growth and non-growth associated constant, respectively. Substituting equation (1) and (2) into (4) and integrating will yield equation (5)

$$
P=P_{0}+\alpha x_{0}\left[\frac{e^{\mu_{m} t}}{1-\left(x_{0} / x_{m}\right)\left(1-e^{\mu_{m} t}\right)}-1\right]+\beta \frac{x_{m}}{\mu_{m}} \ln \left[1-\frac{x_{0}}{x_{m}}\left(1-e^{\mu_{m} t}\right)\right]
$$

Since PHB production starts mainly at exponential phase, the initial PHB concentration, $P_{0}$ was assumed to be negligible. Thus, Equation (5) can be simplified further as

$$
P=\alpha A(t)+\beta B(t)
$$


where $A(t)=x_{0}\left[\frac{e^{\mu_{m} t}}{1-\left(x_{0} / x_{m}\right)\left(1-e^{\mu_{m} t}\right)}-1\right]$ and

$$
B(t)=\frac{x_{m}}{\mu_{m}} \ln \left[1-\frac{x_{0}}{x_{m}}\left(1-e^{\mu_{m} t}\right)\right] \quad \text { respectively. }
$$

At stationary phase, $\frac{d x}{d t}=0$ and $x=x_{m}$. Therefore the value of $\beta$ can be obtained from equation (4). The value of $\alpha$ can be obtained from the linear plot of $P=\beta B(t)$ against $A(t)$

\section{RESUlTS AND DisCUSSION}

In our previous research, the effect of different variables such as urea concentration, jatropha oil concentration and agitation rate on cell growth and PHB production were studied. The cell growth and PHB concentration obtained from bacterial fermentation of $12.5 \mathrm{~g} / \mathrm{L}$ of jatropha oil were presented in Fig. 1. The growth curve has a classical pattern with an exponential phase up to $50 \mathrm{hr}$ followed by stationary phase that lasted until $65 \mathrm{hr}$. Prolonged incubation time lead to decrease in both PHB concentration and CDW. The highest CDW of $11.6 \mathrm{~g} / \mathrm{L}$ was obtained at $55 \mathrm{hr}$ followed by highest PHB concentration of $8.6 \mathrm{~g} / \mathrm{L}$ at $61.5 \mathrm{hr}$.

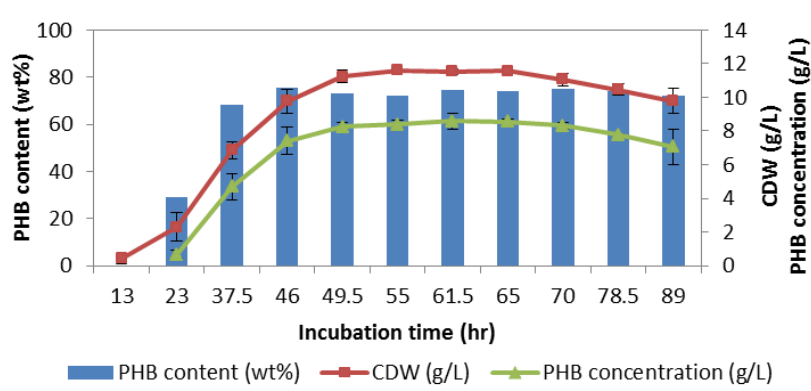

Fig. 1. Cell growth, PHB concentration and PHB content from bacterial fermentation of $12.5 \mathrm{~g} / \mathrm{L}$ Jatropha oil with time. Urea concentration was fixed at $1 \mathrm{~g} / \mathrm{L}$. The cultivation was conducted in $100 \mathrm{~mL}$ shake flasks, and incubated at $30^{\circ} \mathrm{C}$ at $200 \mathrm{rpm}$ for $90 \mathrm{hrs}$. All results were means of duplicate.

Based on the results obtained, the kinetic model for the experimental data was determined by using equations (1) to (6). The linear plot of equation (3) gives the values of $\mu_{\mathrm{m}}$ and $x_{0}$ which are presented in Table I. Substituting these values along with $x_{m}$ obtained from the experimental data into equation (2), yielded the theoretical CDW as depicted in Fig. 2. From the calculated constants, the values for $\mathrm{A}(\mathrm{t})$ and $B(t)$ in equation (6) can be calculated to give the theoretical PHB concentration values (Fig. 2). The experimental data (Fig. 2) matches well with the kinetic model at $\log$ phase and early stationary phase. However, the experimental values deviate slightly towards the end of stationary phase because the logistic equation used does not portray the decrease in cell density that normally occurs at the end of stationary phase [20].

Similarly, the kinetic model for PHB concentration agrees well with the experimental data. The $\alpha$ value $(0.6814 \mathrm{~g} / \mathrm{g})$ obtained was considerably higher than $\beta\left(0.001768 \mathrm{~g} \mathrm{~g}^{-1} \mathrm{~h}^{-1}\right)$ which indicates that the PHB production mostly confirms to the growth associated kinetic pattern and only a small amount of PHB is produced during non-growth stage. The kinetic model appears to overestimate PHB production at the end of stationary phase. This is probably due to PHB degradation at the end of stationary phase that might have caused the PHB concentration to decline. Nevertheless, it should be noted that that the kinetic parameters may vary with change in fermentation condition such as agitation, $\mathrm{pH}$ and substrate concentration. Thus, the kinetic model for different experimental condition should be calculated individually.

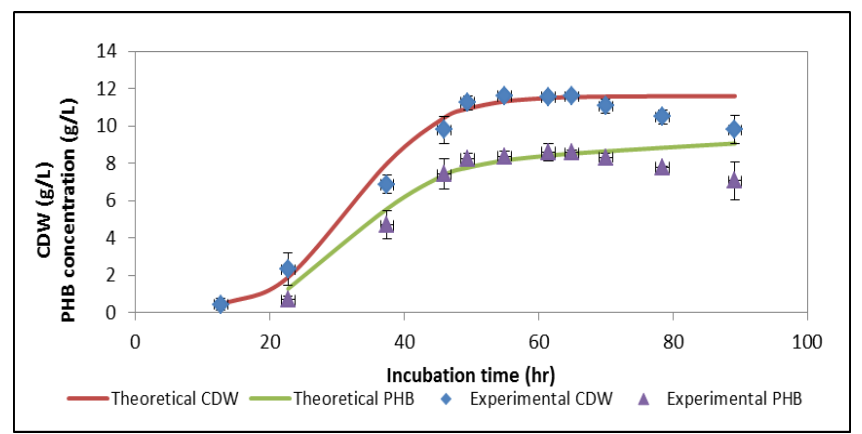

Fig. 2. Kinetic data for microbial cell dry weight and PHB concentration. Oil and urea concentration was fixed at $12.5 \mathrm{~g} / \mathrm{L}$ and $1 \mathrm{~g} / \mathrm{L}$ respectively. The cultivation was conducted in $100 \mathrm{~mL}$ shake flasks, and incubated at $30^{\circ} \mathrm{C}$ at $200 \mathrm{rpm}$ for $90 \mathrm{hrs}$.

TABLE I: SUMMARY OF KINETIC MODEL PARAMETERS
\begin{tabular}{|l|l|}
\hline Constants & Values \\
\hline Cell Growth Rate & 11.59486 \\
$\boldsymbol{x}_{\boldsymbol{m}}(\mathrm{g} / \mathrm{L})$ & 0.1651 \\
$\boldsymbol{\mu}_{\boldsymbol{m}}\left(\mathrm{h}^{-1}\right)$ & 0.0525 \\
$\boldsymbol{x}_{\boldsymbol{\theta}}(\mathrm{g} / \mathrm{L})$ & \\
& \\
Product Formation & \\
Rate & 0.6814 \\
$\alpha(\mathrm{g} / \mathrm{g})$ & 0.001768 \\
$\beta\left(\mathrm{g} \mathrm{g}^{-1} \mathrm{~h}^{-1}\right)$ &
\end{tabular}

\section{CONCLUSION}

Jatropha oil has high potential to be used as carbon source in bacterial biopolymer production. The cell growth and PHB concentration from experimental data agrees well with the logistic and Leudeking-Piret model. The PHB accumulation mostly adhered to growth-associated kinetic pattern with insignificant amount of PHB produced during the non-growth stage.

\section{APPENDIX}

$P \quad$ Product concentration $(\mathrm{g} / \mathrm{L})$

$P_{0} \quad$ Initial product concentration $(\mathrm{g} / \mathrm{L})$

$t \quad$ Time (h)

$t_{m} \quad$ Time when maximum cell concentration reached (h)

$x \quad$ Cell concentration $(\mathrm{g} / \mathrm{L})$

$x_{0} \quad$ Initial cell concentration $(\mathrm{g} / \mathrm{L})$

$x_{m} \quad$ Maximum cell concentration $(\mathrm{g} / \mathrm{L})$

$\alpha \quad$ Growth associated constant $(\mathrm{g} / \mathrm{g})$

$\beta \quad$ Non-growth associated constant $\left(\mathrm{g} \mathrm{g}^{-1} \mathrm{~h}^{-1}\right)$

$\mu_{\max }$ Maximum specific cell growth rate $\left(\mathrm{h}^{-1}\right)$ 


\section{ACKNOWLEDGEMENT}

We would like to express our gratitude to Universiti Malaysia Pahang for providing all the facilities for our research work.

\section{REFERENCES}

[1] M. Luengo et al., "Bioplastics from microorganisms," Ecology and industrial microbiology, pp. 251, 2003.

[2] C. Reddy, G. R. Rashmi, and V. Kalia, "Polyhydroxyalkanoates: an overview," Bioresource Technology, vol. 87, pp. 137-146, 2003.

[3] S. Kulkarni, P. Kanekar, S. Nilegaonkar, S. Sarnaik, and J. Jog, "Production and characterization of a biodegradable poly(hydroxybutyrate-co-hydroxyvalerate) (PHB-co-PHV) copolymer by moderately haloalkalitolerant Halomonas campisalis MCM B-1027 isolated from Lonar Lake, India," Bioresource Technology, vol. 101, pp. 9765, 2010.

[4] B. Rehm, "Bacterial polymers: biosynthesis, modifications and applications," Nat. Rev. Microbiol., vol. 8, pp. 578-592, 2010.

[5] C. Reddy et al., "Polyhydroxyalkanoates: an overview," Bioresource Technology, vol. 87, pp. 137-146, 2003.

[6] J.-I. Choi and S. Y. Lee, "Process analysis and economic evaluation for Poly (3-hydroxybutyrate) production by fermentation," Bioprocess Engineering, pp. 334-342, 1997.

[7] M. Koller, A. Atlic, M. Dias, A. Reiterer, and G. Braunegg, "Microbial PHA Production from Waste Raw Materials," in G.-Q Chen and G.-Q. Chen (Ed.), Plastics from Bacteria: Natural Functions and Applications, Springer-Verlag Berlin Heidelberg, 2010, pp. $85-120$.

[8] A. Chua, H. Takabatake, H. Satoh, and T. Mino, "Production of polyhydroxyalkanoates (PHA) by activated sludge treating municipal wastewater: effect of $\mathrm{pH}$, sludge retention time (SRT), and acetate concentration in influent," Water Res, pp. 3602-3611, 2003.

[9] M. Rodgers and G. Wu, "Production of polyhydroxybutyrate by activated sludge performing enhanced biological phosphorus removal," Bioresource Technology, vol. 10, pp. 1049-1053, 2010.

[10] D. Orhon, E. Gorgun, F. Germirli, and N. Artan, "Biological treatability of dairy wastewaters," Water Resources, vol. 27, pp. 625633, 1993.

[11] S. R. Pandian, V. Deepak, K. Kalishwaralal, N. Rameshkumar, M. Jeyaraj, and S. Gurunathan, "Optimization and fed-batch production of PHB utilizing dairy waste and seawater as nutrient sources by Bacillus megaterium SRKP-3," Bioresource Technology, vol. 101, pp. 705-711, 2005.
[12] D. H. Park and B. S. Kim, "Production of poly(3-hydroxybutyrate) and poly (3-hydroxybutyrate-co-4-hydroxybutyrate) by Ralstonia eutropha from soybean oil," New Biotechnology, 2011.

[13] M. López-Cuellar, J. Alba-Flores, J. G. Rodríguez, and F. PérezGuevara, "Production of polyhydroxyalkanoates (PHAs) with canola oil as carbon source," International Journal of Biological Macromolecules, vol. 48, pp. 75, 2010.

[14] S. N. Ko, Y. O. Wei, K. G. Lay, S. Rajaiah, and S. Kumar, "Evaluation of jatropha oil to produce poly (3-hydroxybutyrate) by Cupriavidus necator H16," Polymer Degradation and Stability, vol. 95, pp. 1365-1369, 2010.

[15] F. Freitas et al., "Recovery of polyhydroxybutyrate (PHB) from Cupriavidus necator biomass by solvent extraction with 1,2-propylene carbonate," Engineering in Life Sciences, pp. 454-461, 2009.

[16] G. Braunegg, B. Sonnleimer, and R. Lafferty, "A Rapid Gas Chromatographic Method for the Determination of Poly-Bhydroxybutyric Acid in Microbial Biomass," European J. Appl. Microbiol.Biotechnol., vol. 6, pp. 29-37, 1978.

[17] P. Verhulst, "Notice sur la loi que la population poursuit dans son accroissement," Correspondance mathématique et physique, vol. 10 , pp. $113-121,1838$

[18] A. Mulchandani, J. H. Luong, and C. Groom, "Substrate inhibition kinetics for microbial growth and synthesis of poly-fl-hydroxybutyric acid by Alcaligenes eutrophus ATCC 17697," Appl Microbiol Biotechnol, vol. 30, pp. 11-17, 1989.

[19] R. Luedeking and E. Piret, "A kinetic study of the lactic acic fermentation. Batch process at controlled pH," J. Biochem. Microbiol. Technol. Eng, vol. 1, no. 4, pp. 393-412, 1959.

[20] D. E. Wachenheim, J. A. Patterson, and M. R. Ladisch, "Analysis of the logistic function model: derivation and applications specific to batch cultured microorganisms," Bioresource Technology, vol. 86, pp. 157-164, 2003.

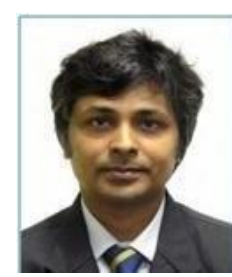

Maksudur Rahman Khan received his B.Sc. M.Sc., and PhD. degrees from the State University L'vivska Polytechnica, Ukraine. His main research interests include heterogeneous catalysis, wastewater treatment, nanoparticle synthesis and fuel cell technology, and biofuel. Currently, he is working in Universiti Malaysia Pahang, Malaysia with on-going research projects in various fields such as photocatalyst development, wastewater treatment by adsorption and so on. 